University of Windsor

Scholarship at UWindsor

\title{
Exploring the Role of School Engagement in Predicting Resilience Among Bahamian Youth
}

Jones Giavana

University of Windsor

Kathryn Lafreniere

University of Windsor

Follow this and additional works at: https://scholar.uwindsor.ca/psychologypub

Part of the Psychology Commons

\section{Recommended Citation}

Giavana, Jones and Lafreniere, Kathryn. (2014). Exploring the Role of School Engagement in Predicting Resilience Among Bahamian Youth. Journal of Black Psychology, 40 (1), 47-68.

https://scholar.uwindsor.ca/psychologypub/46

This Article is brought to you for free and open access by the Department of Psychology at Scholarship at UWindsor. It has been accepted for inclusion in Psychology Publications by an authorized administrator of Scholarship at UWindsor. For more information, please contact scholarship@uwindsor.ca. 


\section{Exploring the role of school engagement in predicting resilience among Bahamian youth}

Giavana Jones, Department of Psychology, University of Windsor

Kathryn Lafreniere, Department of Psychology, University of Windsor

Some individuals beat the odds and overcome seemingly insurmountable challenges, while others who experience similar conditions fall prey to their circumstances. For the past three decades, social scientists have sought to understand the concept of resilience, particularly as it relates to children who are raised in unfavorable circumstances (Mohaupt, 2008). Although the definitions may vary, researchers would agree that in order for resilience to occur, there has to be some risk factor that undermines positive outcomes (Luthar, Cicchetti, \& Becker, 2000; Masten, 2001; Snyder \& Lopez, 2007; Ungar, 2008; Waller, 2001). Additionally, research supports that resilience is best conceptualized as a dynamic and multidimensional process, which is likely to differ from individual to individual and from group to group (Jones, 2007; Ungar, 2008; Waller, 2001). Consequently, context should be considered when assessing resilience, so that the standard of 'wellness' that is accepted by one group or by the dominant culture is not applied to another group or subculture unjustifiably. For example, the American Psychological Association Task Force on Resilience and Strength in Black Children and Adolescents (2008) advocates that in order to fully understand the strengths and resilience of African American children, one must consider the impact of oppression and racial discrimination in the lives of such youth.

According to Bronfenbrenner's ecological theory of human development (Bronfenbrenner, 1979), the environment can be broken down into systems, with the smallest being the microsystem, which includes people that a child has contact with on a regular basis. 
The primary microsystems for most children are the home (family) and the school. In addition to the microsystem, Bronfenbrenner identified another three systems: the mesosystem (representing the links between microsystems, such as degree of parental involvement in schools); exosystem (settings such as school boards that indirectly impact upon the child); and the macrosystem, which is the broadest system, and is comprised of larger societal structures such as cultural, economic, and political influences. These systems are proposed to be connected, such that changes at one level can impact the other levels. As it relates to Bahamian youth, the neighborhood could be considered a mesosystem, as it consists of the connections among residents, and overlaps between the school and family. It is not uncommon for Bahamian students who live within a geographical area not only to attend the same school, but also to be related. It is also important to note that the influences are bidirectional, in that an individual can impact his or her environment, just as the environment impacts that individual's development and behaviors.

\section{Context and Rationale for the Present Study}

The Bahamas is an independent island nation with a population of about 325,000 dispersed among 20 islands just south of Florida, USA (Department of Statistics, 2005). The majority of the population is concentrated on the island of New Providence, where the capital city of Nassau is located (Gomez et al., 2002). Despite the beauty of the beaches and consistently warm climate which attracts tourists yearly, the residents of the islands experience many social ills. The majority of the problems, which stem from poverty, are generally concentrated within the more central areas of New Providence Island. The children raised in these areas subsequently experience numerous challenges, including limited access to the resources that promote educational, emotional and physical development (Bowen, Desimone \& 
McKay, 1995; Cauce, Stewart, Rodriguez, Cochran \& Ginzler, 2003; Department of Statistics, 2004). Specifically, illiteracy, high school drop outs, teen-related violence, and teen sexual risktaking are some of the issues plaguing Bahamian society, and more specifically, these urban areas. Despite the many challenges faced by families living in these urban, impoverished areas, not all the children raised there are falling victim to their circumstances. Some children manage to survive unscathed, and still others are thriving.

Both internal factors and the influences of environmental systems can contribute to positive outcomes in the resilience process (Arrington \& Wilson, 2000; Waller, 2001). In the absence of these "protective factors", at-risk children are less likely to overcome the risks associated with their lives (Luthar et al., 2000; Masten, Herbers, Cutuli, \& Lafavor, 2008; Snyder \& Lopez, 2007). Cognitive ability, self-regulation and self-efficacy are some of the more commonly researched internal or individual level factors that are associated with resilience (Arrington \& Wilson, 2000; Masten et al., 2008; Mohaupt, 2008). Commonly identified environmental factors that have been shown to promote resilience include the role of the family (particularly the parent-child relationship), the school, and the community (Arrington \& Wilson, 2000; Masten et al., 2008).

Self-efficacy refers to an individual's belief in their ability to control their own motivations and behaviors (Bandura, 1990). This control is usually in relation to a specific goal, for example, trying to refrain from maladaptive behaviors or trying to master a skill to attain a particular goal. Specifically, self-efficacy in adolescent populations has been studied in relation to their ability to not engage in certain risky health behaviors, including smoking (Kohler, Schoenberger, Tseng, \& Ross, 2008; van Zundert, van de Ven, Engels, Otten, \& van den Eijnden, 2007), alcohol and drug use (De Vries, Dijkstra, \& Kuhlman, 1988; Fagan et al., 2003) 
and early sexual experiences (Lafflin, Wang, \& Barry, 2008; Wang \& Hsu, 2006). Self-efficacy has also been studied in adolescents in relation to their ability to use condoms effectively (Smith $\&$ DiClemente, 2000; Thato, Hanna, \& Branom, 2005) and to sustain effort toward academic achievement (Bandura, 1990; Usher \& Pajares, 2006).

Bandura (1994) proposed that self-efficacy is developed in four primary ways. The first pathway is through social influences, where someone provides youth with positive feedback about their abilities, acting as a 'cheerleader' to encourage the youth in their endeavors. Selfefficacy is also developed though mastery experiences, where youth have an opportunity to hone their skills and abilities. Youth also develop self-efficacy by seeing others, similar to themselves, successfully manage tasks. The final pathway which aids in the development of self-efficacy is through the youth's own emotional responses. Less efficacious beliefs are usually linked with stress or negative reactions to a particular task; thus, to develop self-efficacy, youth need to learn to replace negative emotions with more positive ones as they relate to a specific task.

Positive and meaningful relationships with adults (familial and non-familial) have consistently been found in the literature to be associated with positive outcomes in youth (Masten \& Coatsworth, 1998; Jones, 2007; Richmond \& Beardslee, 1988; Scales, Benson, \& Mannes, 2006; Ungar, 2008). Similarly, healthy parent-child relationships have been shown to serve as a protective factor for promoting resilience among at-risk populations (Tusaie, Puskar, \& Sereika, 2007; Vanderbilt-Adriance \& Shaw, 2008). Research has indicated that, in the absence of parents, a positive adult, familial or non-familial, can step in to fill the void the absent parent has left (Richmond \& Beardslee, 1988; Scales et al., 2006). In addition, the positive relationships that youth experience have an additive effect on their development, such that the 
more of these relationships in which they are engaged, the better the outcomes (Benson, Scales, Hamilton, \& Sesma, 2006).

Youth workers have suggested that adolescent involvement in activities, both school and non-school related, offer many advantages for the adolescent, even serving as a protective factor for at-risk youth (Benson et al., 2006; Eccles \& Barber, 1999; Eccles, Barber, Stone, \& Hunt, 2003; Zeldin 2004). Such involvement helps to foster a sense of belonging in school, thus making the students who participate more likely to remain in school (Randolph, Fraser, \& Orthner, 2004). Engaging in extracurricular activities also provides an environment where youth can build positive relationships which subsequently help to expand their social support network and decrease the likelihood of involvement in delinquent behavior (Feldman \& Matjasko, 2005; Landers \& Landers, 1978). Finally, involvement in activities provides the opportunity for youth to develop skills that can be used in numerous settings, even as they transition into adulthood (Eccles et al., 2003; Zeldin, 2004).

Similar to the role of extra-curricular activities, the school environment has the potential to enhance socio-emotional as well as academic outcomes in youth by providing an atmosphere where cognitive and social competencies can be developed. However, if students do not feel a sense of belonging or desire to be a part of the school environment, and more specifically, if they do not attend or are not engaged even if they do show up for school, then this function is not served in their lives. This is particularly salient in the lives of minority and/or at-risk youth, where research has shown them to be less likely to attend and successfully complete school as compared to their counterparts (Daly, Shin, Thakral, Selders, \& Vera, 2009; Kenny, Blustein, Chaves, Grossman, \& Gallagher, 2003). 
Daly et al. (2009) define school engagement as the students' efforts regarding school in three areas: attitude, investment and commitment. Although attendance is an aspect of school engagement, the student's cognitive and affective connections with their school are of greater importance in understanding this concept (Brown \& Jones, 2004; Morrison, Brown, D'Incaus, O’Farrell, \& Furlong, 2006). Interest in school engagement dates back about two decades (Kenny, Blustein, Chaves, Grossman, \& Gallagher, 2003; Peet, Powell, \& O’Donnel, 1997); however, it has rarely been included in resilience models. When it is included, it has primarily served as an alternative to the study of school dropout in strengths-based models of academic achievement (Finn \& Rock, 1997; Morrison et al., 2006). School engagement has been found to be negatively associated with poor neighborhood conditions, such that students in such neighborhoods are less likely to be engaged in school, even in the presence of varying levels of social support (Daly et al., 2009). In the same study, age was also found to be negatively related to school engagement such that the older students got, the greater the likelihood of their not being engaged with school. Additionally, school engagement has been shown to be associated with peer norms. Students whose friends are less involved with school and more involved with other negative behaviors are less likely themselves to be engaged with school (Shin, Daly, \& Vera, 2007). School engagement is positively related to academic achievement, such that students who are not engaged in school are more likely to fail and sometimes even drop out of school (Archambault, Janosz, Fallu, \& Pagani, 2009; Dotterer, \& Lowe, 2011; Fredricks, Blumenfeld, \& Paris, 2004). Thus, school engagement becomes an important factor in the lives of at-risk youth, to increase their chances of academic success leading to the successful completion of high school, which positions them for increased opportunities during adulthood. 
All of the above mentioned factors, that is, positive relationships, involvement in extracurricular activity, self-efficacy, and school engagement, impact an individual's development, particularly as it relates to social competence. These factors facilitate the development of basic cognitive, emotional and social skills which are crucial to daily social interactions. This study explored the role of the environment, specifically factors associated with the primary microsystems, parental relationship and school engagement; mesosystems, nonparental relationships and involvement in extracurricular activity; and an internal factor, self-efficacy, in the promotion of healthy social development among a sample of at-risk urban Bahamian students. Specifically, these factors were hypothesized to significantly contribute to overall social adjustment for the youth as measured by the Child and Youth Resilience Measure-28.

\section{Method}

\section{Sample and Procedure}

Data from 103 students were collected through questionnaires which were completed during school hours in November 2010. Prior to administration of the questionnaires, consent to participate was obtained from the parents of the students and assent was given by the students. The school-based sample consisted of 60 Grade 9 students attending a junior high school and 43 Grade 11 students attending a senior high school on New Providence, Bahamas. More than half the students were females (64.4\%), ranging in age from 13-17 years, with a mean age of 14.25 $(\mathrm{SD}=1.26)$. When separated by grade level, the average age for the $9^{\text {th }}$ grade students was $13.57(\mathrm{SD}=.07)$ whereas the mean age for the $11^{\text {th }}$ grade students was $15.70(\mathrm{SD}=.77)$. Grade point average in the Bahamas is calculated on a 4-point scale where a 4.0 is an ' $\mathrm{A}$ ', 3.0 is a ' $\mathrm{B}$ ', 2.0 is a ' $\mathrm{C}$ ' and so on. The average reported GPA for this sample was $2.34(\mathrm{SD}=.53)$. 
Socio-economic status was assessed through a number of culturally relevant questions that the average student would be able to accurately answer. Only $4 \%$ of the students reported being a part of the school lunch program, which is a government-funded initiative for Bahamian families living below the poverty line; however, $21 \%$ reported getting water from the community pump for day-to-day living, indicating that there was no running water within the home. When asked about their family's financial status to provide for their needs, $39 \%$ of the students reported that their family had enough money to meet their basic needs without assistance while another $16 \%$ reported that their family had enough money to purchase luxuries. The remaining $45 \%$ of the students reported that their family did not have sufficient money to meet basic needs, suggesting that these families were of lower SES.

\section{Measures}

All students completed a questionnaire packet that took about 45 minutes to complete. The questions collected basic demographic information, information on resilience and information about the five factors hypothesized to be related to resilience.

Resilience. The Child and Youth Resilience Measure -28(CYRM -28; Ungar, Lee, Callaghan, \& Boothroyd, 2005) was used to measure resilience within the social domain. The questions were answered on 5-point Likert scales, ranging from 1 (Not at All) to 5 (A Lot). The CYRM-28 includes 28 statements that measure three proposed components of youth resilience: individual ("I know how to behave in different social situations"), relational ("I enjoy my caregivers' cultural and family traditions"), and contextual ("I think it is important to serve my community"). The Child and Youth Resilience Measure-28 was found to possess adequate internal consistency in standardization samples of Canadian youth, with Cronbach's alphas ranging from .65 to .91 , and high inter-class correlation coefficient scores across two time points 
for all three subscales ranging from .58-.77 (Liebenberg, Ungar \& Van de Vijver, 2011). Both qualitative (focus groups) and mixed method approaches were undertaken in the development of the CYRM-28 to ensure both content and face validity across samples representing more than ten countries worldwide (Ungar \& Liebenberg, 2011). Of the 28 items making up the CYRM-28, 10 were generated from the responses to interviews conducted with nine Bahamian youth prior to the questionnaire data collection. The interviews were conducted in accordance with the recommendation of Ungar et al. (2005) to increase the cultural relevance of the measure for different populations. In the final analyses, one statement ("I am proud to be Bahamian") was discarded because the responses were too varied and reduced the internal consistency of the entire measure. The remaining 27 items of the Child and Youth Resilience Measure-28 showed strong internal consistency $($ Cronbach's alpha $=.92)$. Higher scores were indicative of greater resilience.

Risk. A subscale from the Bahamian Youth Health Risk Behavioral Inventory (BYHRBI; Stanton et al., 1995) assessed neighborhood conditions and served as the measure of risk for this study. The Bahamian Youth Health Risk Behavioral Inventory (BYHRBI) is a cultural adaptation of the Youth Health Risk Behavior Inventory (YHRBI; Stanton et al., 1995) which has been used in an ongoing longitudinal study in The Bahamas assessing health risk behaviours in preadolescent youth (Cole, Stanton, Deveaux, Harris, Lunn, et.al. 2007). The original scale from the YHRBI was found to have good internal consistency in standardization samples of urban African American youth, with Cronbach's alphas ranging from .74 to .81(Stanton et al., 1995). The Bahamian version of the scale was adapted through ethnographic research and was pilot tested before being implemented (Yu, Clemens, Yang, Li, Stanton, et al., 2006); face, content and cultural validity were assessed through the use of focus groups and consultation with 
a local research team. The subscale used in the present study consists of nine statements which assess the frequency of violence, alcohol and drug usage present in the student's environment (e.g. "How often have you seen a person who lives in your neighborhood drink alcohol?"). The students respond to the questions on a three-point Likert scale ranging from 1 (Very Often) to 3 (Never). However, the values were reverse coded, thus, higher scores indicated more problems in the neighborhood. The internal consistency for these nine items $=.84$.

Self-Efficacy. The New General Self-Efficacy Scale (NGSE; Chen, Gully, \& Eden, 2001) was adapted for use in this study as a measure of self-efficacy. The NGSE is a brief, unidimensional measure of general self-efficacy consisting of 8 items. The NGSE was found to be high in internal consistency in standardization samples, with Cronbach's alphas ranging from .86 to .90 , and to show strong concurrent and predictive validity, based on significant and positive correlations with existing self-efficacy measures and specific occupational self-efficacy scales (Chen et al., 2001). Some of the items were reworded to simplify the language for the students in the present study. For example, the item "I am confident that I can perform effectively on many different tasks" was changed to "I'm sure that I can do well on many different tasks". Respondents rated their agreement with eight statements reflecting their perceptions of their abilities on 5-point Likert scales ranging from 1 (Strongly Disagree) to 5 (Strongly Agree), with higher scores indicating greater self-efficacy. The New General SelfEfficacy scale showed strong internal consistency in the present sample, with a Cronbach's alpha coefficient of .80 .

Parent-Child Relationship. This scale was adapted from the Parent-Adolescent Communication scale (Barnes \& Olson, 1985). Nine of the statements making up this measure assessed open communication (e.g. "I can discuss my beliefs with my mother without feeling 
restrained or embarrassed") and another 10 items measured problem family communication (e.g. "Sometimes I have trouble believing everything my mother tells me") reflecting the items originally used in the Parent-Adolescent Communication scale (Barnes \& Olson, 1985). Cronbach's alpha scores for each subscale in the original validation sample were .87 and .78 and the test-retest reliabilities were .78 and .77 (Barnes \& Olson, 1985). The validity of the scale was supported by its correlation with family satisfaction, family cohesion and family adaptability as well as satisfaction with quality of life (Barnes \& Olson, 1985). The adapted subscales have been included in the Bahamian Youth Health Risk Behavioral Inventory (BYHRBI); the wording of all items remained the same, however instead of "mother", parent was substituted. Additionally, where deemed necessary, an explanatory statement was included to simplify the language in a culturally appropriate way, (e.g. "I can discuss my beliefs with my parent(s) without feeling restrained or embarrassed. [For example, without worrying that he or she would be upset or angry or make fun of me.]"). The responses were arranged on a 5-point Likert scale ranging from 1 (Yes) to $5(\mathrm{No})$. The middle values of the scales included the following descriptors: 2 (Maybe), 3 (Don't know) and 4 (Probably Not). This adaptation of the 19-item scale has been used in other studies and has shown good internal consistency with alpha values ranging from .73-.91 (Cottrell, Yu, Liu, Deveaux, Lunn, et al., 2007; Yang, Stanton, Li, Cottrel, Galbraith, et al., 2007; Yang, Stanton, Cottrell, Kaljee, Galbraith et al., 2006). The authors included an additional five items which specifically addressed the student's perception of the parent-child relationship. Students rated their agreement with these five statements (e.g. "I have a good relationship with my parents/guardians") on the same 5-point scale. In the present study, the internal consistency of the open communication subscale was strong (Cronbach's alpha $=$ .79), while the problem communication subscale showed weaker internal consistency 
(Cronbach's alpha $=.66)$. Consequently, subscales were combined to form a composite scale measuring parent-child relationship. The internal consistency for this 24 -item composite scale in the present sample was .87 .

Nonparental relationship. Three statements, developed by the first author, assessed the presence of positive nonparental relationships in the lives of the students (e.g., "I have someone (who is an adult) other than my parents/guardians who I talk to when something is bothering me."). The scale was assessed for face validity by two community psychology and one nursing researchers prior to being finalized and included as a measure in the study. Students rated their agreement with the three statements on 5-point Likert scales ranging from 1 (Strongly Disagree) to 5 (Strongly Agree). Cronbach's alpha was .81, indicating that there was strong internal consistency for this 3-item measure in this sample.

School Engagement. This measure was developed to assess two theoretically derived sub constructs of school engagement: positive involvement and positive experiences with school. Each subscale consisted of seven statements for a total of fourteen statements making up the measure. The items were generated by the researcher to measure school engagement. This scale was also assessed for face validity prior to being finalized and included as a measure in the study. Students rated their agreement with statements reflecting their perception of and engagement in school (e.g., "I feel supported in my class"). The statements were answered on 5point Likert scales ranging from 1 (Strongly Disagree) to 5 (Strongly Agree). The first subscale, positive involvement in school, consisted of seven statements; it addressed students' perception of school, their desire to participate in school activities (including homework) and their commitment to attend. Cronbach's alpha for the 7-item subscale with the current sample was .72. The other subscale consisted of seven statements which assessed students' positive 
experiences with school, for example their perception of the teachers' and school administrators' feelings about them. It also examined their perceived ability to get help when requested. The internal consistency (Cronbach's alpha) for this subscale with this sample was .67.

Involvement in Extracurricular Activity. Any positive activity, whether school, religious, community or sport, for which the student volunteered and which did not earn any required school credit or community service points was counted as extracurricular activity. Students were asked to list the activities in which they were involved, and the total number of activities listed was used as a measure of engagement in extracurricular activity.

\section{Results}

\section{Descriptive Statistics}

Prior to running the principal analyses, data were checked for accuracy and to ensure that all assumptions for the proposed statistical analyses were met. Means, standard deviations and reliabilities for all scales and subscales are shown in Table 1.

[Table 1 about here]

T-tests were conducted for each of the six scales, with grade and gender as independent variables. No significant differences between Grade 9 and Grade 11 students were found on any of the measures. Males, on average, scored higher $(M=20.75, S D=3.09)$ on the parental relationship scale than did females $(M=19.09, S D=3.44), t(97)=2.40, p<.05$. Males also had higher self-efficacy scores $(M=35.58, S D=3.14)$ than their female counterparts $(M=33.88, S D$ $=4.22), t(97)=2.11, p<.05$. There were no significant gender differences for the measures of involvement in extracurricular activity, positive experience and involvement with school, and resilience. 
Seventy two percent of the participants reported that their mothers completed high school, and 63\% reported that their fathers completed high school. There were no significant relationships between parental completion or non-completion of high school and students' own involvement and experience with school.

Correlational analyses (Table 2) confirmed that stronger parent-child relationships were positively associated with higher resilience scores, $r(97)=.55, p<.001$. Additionally, students who reported greater involvement in extracurricular activities scored higher on the Child and Youth Resilience Measure-28, $r(86)=.38, p<.001$. The more involved the students were in school, the higher their resilience scores, $r(97)=.41, p<.001$. Similarly, the more positively the students rated their experience with school, the higher their resilience scores, $r(97)=.27, p<$ .001. Finally, students' higher perceived self-efficacy was positively associated with higher resilience scores, $r(97)=.45, p<.001$.

[Table 2 about here]

\section{Hierarchical Multiple Regression}

A hierarchical multiple regression analysis was conducted to test the hypothesis that parental and other adult relationships, school engagement, involvement in extracurricular activity and perceived self-efficacy would predict resilience. The predictors were entered into the analysis as three blocks. The two variables that focused on the students' relationships were included in block one. These variables were separated from the other environmental factors and included first because research has provided the strongest evidence for the role of healthy relationships in promoting positive outcomes in at-risk youth. The second block contained the remaining environmental factors: positive involvement with school and positive experiences with school (subscales of school engagement) and involvement in extracurricular activities. Finally, 
perceived self-efficacy was included in the final block, after all the environmental factors, to distinguish its contribution above and beyond the other factors. In the initial regression analysis, the positive experiences with school subscale did not significantly contribute to the prediction of resilience $(\beta=-.011, p=.901)$. Consequently, the positive experiences with school variable was excluded from the analysis and the hierarchical regression analysis was rerun to provide a more parsimonious solution. The final regression model is presented in Table 3.

[Table 3 about here]

The first block of variables, which consisted of parental and nonparental relationships, was significant and accounted for approximately $39 \%$ of the variance in resilience, $R^{2}=.39, F$ $(2,85)=26.85, p<.001$. Examination of the squared semi-partial correlation coefficients indicates that both parental relationships $\left(s r^{2}=.30\right)$ and nonparental adult relationships $\left(s r^{2}=\right.$ .09) made significant unique contributions to the prediction of resilience, accounting for $30 \%$ and $9 \%$ of the variance, respectively. The addition of the two remaining environmental factors to the regression model in step 2 resulted in a significant change in $R^{2}$ ( $R^{2}$ change $=.10, p<$ .001). In this block, all included variables were significant predictors of resilience. More specifically, parental relationships, nonparental relationships, engagement in extracurricular activity and involvement in school accounted for $23 \%, 6 \%, 3 \%$, and $3 \%$ of the unique variance in resilience respectively. The addition of self-efficacy to the regression model in the final step also resulted in a significant change in $R^{2}\left(R^{2}\right.$ change $\left.=.06, p<.001\right)$, suggesting that the inclusion of self-efficacy significantly improved the prediction of resilience in this sample. In this block, all variables except involvement in school were significant. Resilience was significantly predicted by parental relationships $(\boldsymbol{\beta}=.43, \mathrm{p}<.001)$, self-efficacy $(\boldsymbol{\beta}=.26, \mathrm{p}<.05)$, nonparental relationships $(\boldsymbol{\beta}=.21, \mathrm{p}<.05)$, and involvement in extracurricular activities $(\boldsymbol{\beta}=.23$, 
$\mathrm{p}<.05)$; these variables accounted for $17 \%, 6 \%, 4 \%$, and $4 \%$ of the unique variance in resilience respectively. The final model was significant and accounted for $55 \%$ of the variance in resilience, $R^{2}=.55, F(5,82)=19.92, p<.001$.

\section{Discussion}

The present study sought to understand the resilience process among a sample of at-risk urban Bahamian adolescents. It was guided by an ecological perspective, acknowledging the impact of the adolescents' environment on their development. Throughout the study, the students' microsystems, i.e., family and school, and their mesosystems, i.e., the connections between their microsystems, were considered in relation to understanding risk and resilience in this population. This study defined resilience in terms of the students' social competence as measured with the Child and Youth Resilience Measure-28. Socially competent youth are able to communicate and participate in various social relationships, monitor and adjust their behavior as it relates to impacting others and demonstrate adequate problem solving and decision making skills (Gullotta, 1990). The development of social competence begins in early childhood and draws from both internal and external resources. In the face of adversity, particularly negative environmental norms, as is the case of the youth in this study, it is expected that social development will be impaired as youth emulate what is modeled; however, this is not always the case. The results indicated that the presence of parental relationships, youths' perceived selfefficacy, the presence of nonparental relationships, involvement in extracurricular activity, and school engagement were all significantly positively correlated with resilience. Additionally, all of these factors, except school engagement, were significant predictors of resilience in the final model.

Two subscales were used in the present study to understand the youths' engagement with school. The first subscale measured the degree of involvement in school and was included in the 
resilience model; the other subscale assessed students' positive experiences with school. Both variables were found to be significantly related to resilience, such that students who reported more positive school experiences and greater involvement in school scored higher on the Child and Youth Resilience Measure-28. When positive involvement in school was included in the resilience model with parental and nonparental relationships and involvement in extracurricular activity, it significantly predicted resilience, accounting for $6 \%$ of the unique variance in explaining resilience in this sample. However, upon adding self-efficacy to the model, positive involvement in school was no longer a significant predictor. Essentially, the results of this study confirm that more socially competent students are more likely to be involved in school; however, when school engagement is combined with other variables, particularly the presence of positive adult relationships and perceived self-efficacy, it is not as strong a predictor. This was an interesting finding that would benefit from further research.

Culturally the Bahamian family system is very close-knit, where parents, grandparents, aunts/uncles and other extended family members play an important role in the socialization of the youth. Additionally, Bahamian youth are also commonly raised by grandmothers in conjunction with, or sometimes in the absence of biological parents similar to the family dynamics of African American youth (American Psychological Association, Task Force on Resilience and Strength in Black Children and Adolescents, 2008). Thus, the results of the current study, where the parental relationship was the strongest predictor of resilience, are not surprising. This finding is also consistent with the trends found within the larger body of literature which has shown parental relationships to be an important and positive aspect in promoting healthy outcomes (Bowen \& Chapman, 1996; Malecki \& Demaray, 2006). Our results confirm the importance of Bahamian parents fostering open and positive relationships 
with their teenagers. Unfortunately, parents are sometimes absent from the lives of their children for a myriad of reasons. Although this is an undesirable situation, the results of the present study support the idea that having a relationship with a nonparental adult is also positively related to good outcomes and predictive of resilience among this sample of Bahamian youth.

Self-efficacy was the second strongest predictor of resilience in this sample. Because it was the only internal factor assessed, it was the last to be included in the model, after all the environmental factors, in order to distinguish its role above and beyond the other factors. Past research has shown the importance of perceived self-efficacy across the lifespan, and especially during the period of adolescence, as it relates to their ability to make healthy decisions (Smith \& DiClemente, 2000; Thato et al., 2005). Self-efficacy is a characteristic that potentially has great value among at-risk populations who are surrounded by negative peer, family and community norms. Students with greater sense of general self-efficacy are more likely to feel a sense of control within their environments, thus enabling them to choose positive peer groups and positive activities to participate in. Additionally, these individuals are more likely to have better developed decision making skills, which are all important aspects of socialization for a teenager. Bahamian youth in particular, will need to believe in their abilities to successfully maneuver challenging school systems, to refrain from joining neighborhood gangs, and to make decisions to abstain from drug and alcohol use. Although self-efficacy is an internal factor, it is built upon strengths within the youth's social network. Parents, guardians, relatives, neighbors and teachers all have a potentially positive role to play in the development of self-efficacy in adolescence (Nebbitt, 2009). Positive individuals can serve as models for the youth, while also providing support, which in turn will help youth gain confidence in their abilities. Additionally, positive 
environments, especially the school, are ideal for providing youth with opportunities for mastery, inside and out of the classroom.

Participating in extracurricular activity serves a number of purposes in adolescent development, all of which are positive, and promote healthy adjustment (Eccles et al., 2003; Zeldin, 2004). The role of involvement in extracurricular activity was assessed in this study and found not only to be positively related to resilience but also to predict resilience in the final model assessed. These findings indicated that those students who reported being involved in activities outside of required school programs were more resilient. Students identified participating in a variety of activities, including religious organizations, such as youth group and dance, sporting activities including track clubs and basketball teams, school clubs, bands, and cultural activities, including the popular cultural festival of Junkanoo. Participation in such activities not only expands the students' networks with positive, like-minded peers, but also places them in settings where they learn basic communication and social skills while increasing students' connections with and commitment to their communities. Furthermore, involvement in positive activities engages, distracts and more importantly gives the adolescents something to look forward to, where they can have fun while also gain life skills for optimal development. Unfortunately, a number of factors may impede youth from participating in extracurricular activities, even if such opportunities are available free of charge. In the absence of structured transportation systems, it is the sole responsibility of the parent/guardian to transport the student to and from the organizations that offer various activities. This arrangement may not always be feasible for families. Even when those activities are held on the school campus, it may be challenging for some youth to stay behind due to their responsibilities in the home. It is not uncommon for a parent/guardian to be holding multiple jobs in order to provide 
for their family. While the parent/guardian is working, some youth are required to stay at home to babysit younger siblings and family members and assist with household chores. If youth are in these situations, then there is very little time for them to participate in any activities outside of those that are required, such as school.

The results of the present study provided evidence that individual, family and community level factors help to promote positive outcomes for students in spite of the challenges they faced due to poverty and undesirable neighborhood conditions. However, some limitations of the study should be noted. There is a possibility of selection bias due to method of recruitment. Less than $30 \%$ of the sampled population participated in this study; students self-selected to participate in the study by choosing to take the consent form home and returning the signed copy to school in a timely manner. Those students who took the forms home, got them signed and returned them to the school might be more organized and reliable than the students who failed to return the consent forms. This possibility reduces the generalizability of the findings to the general student population, particularly since the response rate was less than $50 \%$.

Social desirability bias might be salient in this study because all of the responses were based on self-report data. Future research would be strengthened by the inclusion of teacher and/or parent reports to provide a more objective understanding of the youth and their behaviors. Finally, because resilience is conceptualized as a dynamic process, it is possible that individuals who exhibited strong social competence in this study, as measured by the Child and Youth Resilience Measure-28, may have had periods previously where they exhibited less resilient attitudes and behaviors or may not continue in this trajectory; thus, a longitudinal design would have better captured the resilience process of the students. 
The results of the study add to the literature in understanding the process of resilience in black non-North American samples. It is one of the first studies to specifically look at resilience among Bahamian youth. Additionally, this study also makes a unique contribution to the literature because of the inclusion of school engagement as a predictor of resilience, which is a fairly novel concept within resilience research. Although it was not a significant predictor in the final model, the results have implications for the importance of school engagement to youth, while recognizing that there are potentially more powerful factors in predicting resilience. Acknowledging the importance of the school environment, it behooves school officials, school policy makers and teachers to create atmospheres within the school setting that are positive and stimulating for all; this should, in turn facilitate school engagement even for the outcast, the 'trouble maker' or the academically challenged student. Overall, the findings of the present study increase our understanding of resilience, at-risk Bahamian youth and their experiences with school. 


\section{References}

American Psychological Association, Task Force on Resilience and Strength in Black Children and Adolescents. (2008). Resilience in African American children and adolescents: A vision for optimal development. Washington, DC: Author. Retrieved from http://www.apa.org/pi/cyf/resilience.html

Arrington, E. G., \& Wilson, M. N. (2000). A re-examination of risk and resilience during adolescence: Incorporating culture and diversity. Journal of Child and Family Studies, 9, 221-230.

Bandura, A. (1994). Self-efficacy. In V. S. Ramachaudran (Ed.), Encyclopedia of human behavior, 4. New York: Academic Press, pp. 71-81.

Bandura, A. (1990). Perceived self-efficacy in the exercise of control over AIDS infection. Evaluation and Program Planning, 13, 9-17. doi: 10.1016/0149-7189(90)90004-G

Barnes, H. L., \& Olson, D. H. (1985). Parent-adolescent communication and the Circumplex model. Child Development, 56, 438-447.

Benson, P. L., Scales, P., Hamilton, S., \& Sesma, A. Jr. (2006). Positive youth development: Theory, research, and applications. In Richard M. Lerner (Ed.), Handbook of child psychology (6 $6^{\text {th }}$ Edition): Volume 1, Theoretical models of human development (pp. 894 941). Hoboken, NJ: John Wiley and Sons, Inc.

Bowen, G. L., \& Chapman, M. V. (1996). Poverty, neighborhood danger, social support, and the individual adaptation among at-risk youth in urban areas. Journal of Family Issues, 17, 641-666. doi: 10.1177/019251396017005004

Bronfenbrenner, U. (1979). The ecology of human development: Experiments by nature and design. Cambridge, MA: Harvard University Press. 
Brown, W. T., \& Jones, J. M. (2004). The substance of things hoped for: A study of the future orientation, minority status perceptions, academic engagement, and academic performance of black high school students. Journal of Black Psychology, 30(2), 248-273. doi:10.1177/0095798403260727

Chen, G., Gully, S. M., \& Eden, D. (2001). Validation of a new General Self-Efficacy scale. Organizational Research Methods, 4(1), 62-83. doi: 10.1177/109442810141004

Cole, M., Stanton, B., Deveaux, L., Harris, C., Lunn, S., Cottrell, L. et al. (2007). Latent class analysis of risk behaviors among Bahamian young adolescents: Relationship between values prioritization and latent class. Social Behavior and Personality, 35, 1061-1076.

Cottrell, L., Yu, S., Liu, H., Deveaux, L., Lunn, S., Bain, R. M., \& Stanton, B. (2007). Genderbased model comparisons of maternal values, monitoring, communication, and early adolescent risk behavior. Journal of Adolescent Health, 41(4), 371-379. doi:10.1016/j.jadohealth.2007.05.006

Daly, B. P., Shin, R. Q., Thakral, C., Selders, M., \& Vera, E. (2009). School engagement among urban adolescents of color: Does perception of social support and neighborhood safety really matter? Journal of Youth and Adolescence, 38, 63-74. doi: 10.1007/s10964-0089294-7

Department of Statistics, Bahamas (2005). Vital Statistics Report 2005. Retrieved from http://statistics.bahamas.gov.bs/key.php?cmd=view\&id=75.

Department of Statistics, Bahamas (2004). Bahamas Living Conditions Survey 2001. Retrieved from http://statistics.bahamas.gov.bs/archives.php?cmd=view\&id=2. 
De Vries, H., Dijkstra, M., \& Kuhlman, P. (1988). Self-efficacy: The third factor besides attitude and subjective norm as a predictor of behavioral intentions. Health Education Research, 3, 273-282. doi: 10.1093/her/3.3.273

Dotterer, A. M., \& Lowe, K. (2011). Classroom context, school engagement, and academic achievement in early adolescence. Journal of Youth and Adolescence, 40(12), 1649-1660. doi:10.1007/s10964-011-9647-5

Eccles, J. S., \& Barber, B. L (1999). Student council, volunteering, basketball, or marching band: What kind of extracurricular involvement matters? Journal of Adolescent Research, 14, 10-43.

Eccles, J. S., Barber, B. L., Stone, M., \& Hunt, J. (2003). Extracurricular activities and adolescent development. Journal of Social Issues, 59, 865-889.

Fagan, P, Eisenberg, M., Frazier, L., Stoddard, A. M., Avrunin, J. S., \& Sorensen, G. (2003). Employed adolescents and beliefs about self-efficacy to avoid smoking. Addictive Behaviors, 28, 613-626. doi:10.1016/S0306-4603(02)00227-7

Feldman, A. F., \& Matjasko, J. L., (2005). The role of school-based extracurricular activities in adolescent development: A comprehensive review and future directions. Review of Educational Research, 75, 159-210. doi: 10.3102/00346543075002159

Finn, J. D., \& Rock, D. A. (1997). Academic success among students at risk for school failure. Journal of Applied Psychology, 82(2), 221-234. doi:10.1037/0021-9010.82.2.221

Fredricks, J.A., Blumenfeld, P.C., \& Paris, A.H. (2004). School Engagement: Potential of the concept, state of the evidence. Review of Educational Research, 74, 59-109.

Gomez, M. P., Kimball, A., Orlander, H., Bain, R. M., Fisher, L. D., \& Holmes, K. K. (2002). Epidemic crack cocaine use linked with epidemics of genital ulcer disease and 
heterosexual HIV infection in the Bahamas: Evidence of impact of prevention and control measures. Sexually Transmitted Diseases, 29(5), 259-265.

Gullotta, T. P. (1990). Preface. In Gullotta, T. P., Adams, G. R., \& Montemayor, R. (eds.). Developing social competency in adolescence, (pp. 7-8). Newbury Park, CA: Sage Publications.

Jones, J. M. (2007). Exposure to chronic community violence: Resilience in African American children. Journal of Black Psychology, 33(2), 125-149. doi:10.1177/0095798407299511

Kenny, M., Blustein, D., Chaves, A., Grossman, J., \& Gallagher, L. (2003). The role of perceived barriers and relational support in the educational and vocational lives of high school students. Journal of Counseling Psychology, 50(2), 142-155.

Kohler, C. L., Schoenberger, Y., Tseng, T., \& Ross, L. (2008). Correlates of transitions in stage of change for quitting among adolescent smokers. Addictive Behaviors, 33, 1615-1618.

Lafflin, M. T., Wang, J., \& Barry, M. (2008). A longitudinal study of adolescent transition from virgin to nonvirgin status. Journal of Adolescent Health, 42 (3), 228-236.

Landers, D. M., \& Landers, D. M. (1978). Socialization via interscholastic athletics: Its effects on delinquency. Sociology of Education, 51, 299-303.

Liebenberg, L., Ungar, M., \& Van, d. V. (2012). Validation of the child and youth resilience measure-28 (CYRM-28) among canadian youth. Research on Social Work Practice, $22(2), 219-226$.

Luthar, S.S., Cicchetti, D., \& Becker, B. (2000). The construct of resilience: A critical evaluation and guidelines for future work. Child Development, 71, 543-562. doi: 10.1111/14678624.00164 
Malecki, C. K., \& Demaray, M. K. (2006). Social support as a buffer in the relationship between socioeconomic status and academic performance. School Psychology Quarterly, 21, 375395. Retrieved from http://ft.csa.com.ezproxy.uwindsor.ca/ids70/resolver.php

Masten, A. S. (2001). Ordinary magic: Resilience processes in development. American Psychologist, 56, 227-238. doi: 10.1037//0003-066X.56.3.227

Masten, A. S., \& Coatsworth, J. D. (1998). The development of competence in favorable and unfavorable environments: Lessons from research on successful children. American Psychologist, 53, 205-220. Retrieved from http://ft.csa.com.ezproxy.uwindsor.ca/ids70/resolver.php

Masten, A. S., Herbers, J. E., Cutuli, J. J., \& Lafavor, T. L. (2008). Promoting competence and resilience in the school context. Professional School Counseling, 12(2), 76-84.

Mohaupt, S. (2008). Review article: Resilience and social exclusion. Social Policy \& Society 8(1), 63-71. doi:10.1017/S1474746408004594

Morrison, G. M., Brown, M., D’Incaus, B., O’Farrell, S. L., \& Furlong, M. (2006). Understanding resilience in educational trajectories: Implications for protective possibilities. Psychology in the Schools, 43(1), 19-31. doi: 1 0.1002/pits.20126

Nebbitt, V. (2009). Self-efficacy in African American adolescent males living in urban public housing. Journal of Black Psychology, 35(3), 295-316. doi:10.1177/0095798409333616

Peet, S. H., Powell, D. R., \& O’Donnel, B. K. (1997). Mother-teacher congruence in perceptions of the child's competence and school engagement: Links to academic achievement. Journal of Applied Developmental Psychology, 18, 373-393.

Randolph, K. A., Fraser, M. W., \& Orthner, D. K. (2004). Educational resilience among youth at risk. Substance Use and Misuse, 39, 747-767. doi: 10.1081/JA-120034014 
Richmond, J. G., \& Beardslee, W. R. (1988). Resiliency: Research and practical implications for pediatricians. Developmental and Behavioral Pediatrics, 9(3), 157-163.

Scales, P. C., Benson, P. L., \& Mannes, M. (2006). The contribution to adolescent well-being made by nonfamily adults and examination of developmental assets as contexts and processes. Journal of Community Psychology, 34, 401-413. doi: 10.1002/jcop.20106

Shin, R., Daly, B., \& Vera, E. (2007). The relationships of peer norms, ethnic identity and peer support to school engagement in urban youth. Professional School Counseling, 10, 379388.

Smith, M. U., \& DiClemente, R. J. (2000). STAND: A peer educator training curriculum for sexual risk reduction in the rural South. Preventive Medicine, 30, 441-449. doi: 10.1006/pmed.2000.0666

Snyder, C. R., \& Lopez, S. J. (2007). Positive psychology: The scientific and practical explorations of human strengths. Thousand Oaks, CA: Sage Publications.

Stanton, B., Black, M., Feigelman, S., Ricardo, I., Galbraith, J., Li, X., et. al. (1995). Development of a culturally, theoretically and developmentally based survey instrument for assessing risk behaviors among African-American early adolescents living in urban low income neighborhoods. AIDS Education and Prevention: An Interdisciplinary Journal, 7, 160-177.

Thato, S., Hanna, K. M., \& Branom, R. (2005). Translation and validation of the Condom SelfEfficacy Scale with Thai adolescents and young adults. Journal of Nursing Scholarship, 37, 36-40. doi: 10.1111/j.1547-5069.2005.00012.x 
Tusaie, K., Puskar, K., \& Sereika, S. M. (2007). A predictive and moderating model of psychosocial resilience in adolescents. Journal of Nursing Scholarship, 39, 54-60. doi: 10.1111/j.1547-5069.2007.00143.x

Ungar, M. (2008). Resilience across cultures. British Journal of Social Work, 38, 218-235. doi: 10.1093/bjsw/bcl343

Ungar, M., \& Liebenberg, L. (2011). Assessing resilience across cultures using mixed methods: Construction of the child and youth resilience measure. Journal of Mixed Methods Research, 5(2), 126-149. doi:10.1177/1558689811400607

Ungar, M., Lee, A. W., Callaghan, T., \& Boothroyd, R. A. (2005). An international collaboration to study resilience in adolescents across cultures. Journal of Social Work Research and Evaluation, 6(1), 5-23.

Usher, E. L., \& Pajares, F. (2006). Sources of academic and self-regulatory efficacy beliefs of entering middle school students. Contemporary Education Psychology, 31, 125-141. doi: 10.1016/j.cedpsych.2005.03.002

van Zundert, R M., van de Ven, M. O. M., Engels, R. C. M. E., Otten, R., \& van den Eijnden, R. J. J. M. (2007). The role of smoking-cessation-specific parenting in adolescent smokingspecific cognitions and readiness to quit. Journal of Child Psychology and Psychiatry and Allied Disciplines, 48(2), 202-209. doi:10.1111/j.1469-7610.2006.01693.x.

Vanderbilt-Adriance, E., \& Shaw, D. S. (2008). Protective factors and the development of resilience in the context of neighborhood disadvantage. Journal of Abnormal Child Psychology, 36(6), 887-901.

Voelkl, K. E. (1997). Identification with school. American Journal of Education, 105, 204-319. 
Waller, M. (2001). Resilience in ecosystemic context: Evolution of the concept. American Journal of Orthopsychiatry, 71, 290-297.

Wang, R., \& Hsu, H. (2006). Correlates of sexual abstinence among adolescent virgins dating steady boyfriends in Taiwan. Journal of Nursing Scholarship, 38(3), 286-291.

Yang, H., Stanton, B., Li, X., Cottrel, L., Galbraith, J., \& Kaljee, L. (2007). Dynamic association between parental monitoring and communication and adolescent risk involvement among african-american adolescents. Journal of the National Medical Association, 99(5), 51724.

Yang, H., Stanton, B., Cottrel, L., Kaljee, L., Galbraith, J., Li, X., Cole, M., Harris, C. \& Wu, Y. (2006). Parental awareness of adolescent risk involvement: Implications of overestimates and underestimates. Journal of Adolescent Health, 39(3), 353-361.

doi:10.1016/j.jadohealth.2005.12.008

Yu, S., Clemens, R., Yang, H., Li, X., Stanton, B., Deveaux, L., Lunn, S., Cottrell, L ., \& Harris, C. (2006). Youth and parental perceptions of parental monitoring and parent-adolescent communication, youth depression, and youth risk behaviors. Social Behavior and Personality, 34(10), 1297-1310. doi:10.2224/sbp.2006.34.10.1297

Zeldin, S. (2004). Preventing youth violence through the promotion of community engagement and membership. Journal of Community Psychology, 32, 623-641. doi:

10.1002/jcop. 20023 
Table 1

Means, Standard Deviations, and Reliabilities for Scales and Subscales

\begin{tabular}{lllllll}
\hline Scale & Possible & Actual & $n$ & $M$ & $S D$ & $\alpha$ \\
& Range & Range & & & & \\
& & & & &
\end{tabular}

Relationship with

$\begin{array}{lllllll}\text { parents } & 24-120 & 35-117 & 102 & 79.59 & 18.27 & .87\end{array}$

Relationship with

nonparental adult

$\begin{array}{lllll}3-15 & 3-15 & 103 & 10.94 & 3.38\end{array}$

.81

School Engagement

Positive

Experiences with

school

7-35 11-35

103

25.11

4.79

.67

Positive

involvement with

school

$7-35$

$10-35$

$103 \quad 26.14$

5.15

.72

Self-Efficacy

$8-40$

$19-40$

103

34.44

$3.91 \quad .80$

Extracurricular

Activity

$\begin{array}{llllll}\mathrm{n} / \mathrm{a} & 0-8 & 103 & 2.62 & 2.00 & \mathrm{n} / \mathrm{a}\end{array}$

Risk

$\begin{array}{llllll}11-33 & 13-33 & 103 & 20.60 & 5.38 & .84\end{array}$

CYRM-28

37-185 95-185

$99 \quad 152.65$

21.65

.92

${ }^{* *} p<0.01$

$* p<0.05$ 
Table 2

\section{Correlations}

\begin{tabular}{|c|c|c|c|c|c|c|c|c|c|}
\hline Variables & 1 & 2 & 3 & 4 & 5 & 6 & 7 & 8 & 9 \\
\hline 1. Relationship with & 1.00 & & & & & & & & \\
\hline \multicolumn{10}{|l|}{ Parent } \\
\hline 2. Relationship & .05 & 1.00 & & & & & & & \\
\hline \multicolumn{10}{|l|}{ (nonparental) } \\
\hline 3. Positive Involvement & $.37^{* *}$ & .03 & 1.00 & & & & & & \\
\hline \multicolumn{10}{|l|}{ (school) } \\
\hline 4. Positive Experience & $.30^{* *}$ & .04 & $.41^{* *}$ & 1.00 & & & & & \\
\hline \multicolumn{10}{|l|}{ (school) } \\
\hline 5. Extracurricular & -.02 & $.23^{*}$ & $.37^{* *}$ & .16 & 1.00 & & & & \\
\hline \multicolumn{10}{|l|}{ Activity } \\
\hline 6. Self-Efficacy & $.30^{* *}$ & .18 & $.26^{* *}$ & .17 & .04 & 1.00 & & & \\
\hline 7. CYRM-28 & $.49^{* *}$ & $.27^{* *}$ & $.41^{\text {*** }}$ & $.27^{* *}$ & $.38^{* *}$ & $.45^{* *}$ & 1.00 & & \\
\hline 8. Gender & $-.24^{*}$ & -.00 & -.01 & -.14 & .09 & $-.21^{*}$ & -.11 & 1.00 & \\
\hline 9. Grade & .08 & -.04 & .02 & .17 & .06 & .01 & -.00 & $-.20^{*}$ & 1.00 \\
\hline
\end{tabular}

$$
{ }^{* *} p<0.01
$$$$
{ }^{*} p<0.05
$$ 
Table 3

Hierarchical multiple regression analyses predicting resilience $(N=87)$

\begin{tabular}{|c|c|c|c|}
\hline Predictors & $\boldsymbol{\beta}$ & $s r^{2}$ & $\Delta R^{2}$ \\
\hline Step 1 & & & .39 \\
\hline Parental Relationship & $.56^{* *}$ & .30 & \\
\hline Relationship (nonparental) & $.31^{*}$ & .09 & \\
\hline Step 2 & & & .10 \\
\hline Parental Relationship & $.50^{* *}$ & .23 & \\
\hline Relationship (nonparental) & $.26^{*}$ & .06 & \\
\hline Positive Involvement (school) & $.19^{*}$ & .03 & \\
\hline Extracurricular Activity & $.20^{*}$ & .03 & \\
\hline Step 3 & & & .06 \\
\hline Parental Relationship & $.43^{* *}$ & .17 & \\
\hline Relationship (nonparental) & $.21^{*}$ & .04 & \\
\hline Positive Involvement (school) & .13 & .01 & \\
\hline Extracurricular Activity & $.23^{*}$ & .04 & \\
\hline Self-Efficacy & $.26^{*}$ & .06 & \\
\hline$* * p<0.01$ & & & $\mathrm{R}^{2}$ model $=.55$ \\
\hline$* p<0.05$ & & & $\mathrm{R}=.74^{* *}$ \\
\hline
\end{tabular}

